\title{
Shortfall of equipment for neonatal intensive care and the introduction of budget holding contracts
}

\author{
Alan C Fenton, David J Field
}

\begin{abstract}
As adequate allowance must be made for the costs of purchasing, maintaining, and updating equipment during the development of contracts the current standing of neonatal units with regard to available equipment was assessed. Data were collected as part of a one year prospective survey of the 17 perinatal units in the Trent region. Adequacy of provision of equipment for recognised intensive care cots was assessed using the recommendations of the British Paediatric Association and British Association of Perinatal Paediatrics. It was assumed that units without recognised intensive care cots had to be able to equip one cot to a standard of intensive care level 1 in the short term. Equipment more than 5 years old was considered likely to warrant replacement or major maintenance within the next two years. With these guidelines over $£ 600000$ would be required to provide sufficient equipment for all recognised level 1 intensive care cots and to allow units without funded cots to provide this level of care in the short term and to replace existing equipment more than 5 years old for these cots alone. This amount could be reduced by $25 \%$ by subdividing intensive care cots into levels 1 and 2 , thereby reducing equipment requirements, but this would impair the units' ability to perform level 1 care at funded provision, which has already been shown to need expansion. Neither figure takes account of equipment requirements for infants requiring special care. In addition, no allowance has been made for purchase or update of ultrasound scanners or blood gas analysers.

If the government's proposed reforms are to be implemented clinicians need to revise guidelines regarding essential equipment, and plans must be made to correct any existing shortfalls so that they do not become inherited financial liabilities for future budget holders.
\end{abstract}

\section{Introduction}

Neonatal intensive care is expensive, the cost for each infant increasing with increasing degree of prematurity. ${ }^{1}$ In addition to running costs, establishing and maintaining a neonatal intensive care service requires a high input in several areas. Adequate provision of resources for appropriately experienced medical and nursing staff is essential. ${ }^{2}$ Another important topic that has received comparatively little attention concerns purchase, maintenance, and replacement of equipment.

To undertake any intensive care requires a certain amount of supportive and monitoring equipment. The only recommendations for what constitutes essential equipment are currently more than five years old (appendix) ${ }^{3}$ and do not include items such as saturation

monitors that have only recently become widely used.
Any equipment must satisfy certain basic requirements in terms of reliability and useful lifespan to be of value: most of this equipment needs to be available continuously in order to minimise capital expenditure. Some provision must also be made for updating or replacing items.

Neonatal intensive care cots are at a premium, ${ }^{4}$ and therefore the service provided might be well suited to the marketplace economy for health services proposed in the white paper Working for Patients. Budget holding units would not, however, want to use their funds immediately for purchasing or replacing expensive equipment. We therefore wished to assess the current state of neonatal equipment on a regional basis.

\section{Methods}

As part of a one year prospective study of the perinatal services in the Trent region carried out from 31 January 1987 to 1 February 1988 the staff of the 17 neonatal units were asked to supply details of current equipment and its age. Using the British Paediatric Association and British Association of Perinatal Paediatrics recommendations for the provision of equipment for intensive care we assessed whether the amount of equipment actually available was adequate for the service provided and sufficient to equip appropriately the number of intensive care cots theoretically allocated to each unit. We also estimated the proportion of existing equipment that might need replacement soon. From these data we calculated the capital outlay required to achieve satisfactory levels of monitoring and supportive equipment for the region's perinatal units.

A questionnaire was completed by each neonatal unit regarding details of all the equipment available during the study period. In addition to the total, the number of items of equipment over 5 years old was noted.

The number of intensive care cots allowed for in the nursing establishment at the time of the study and the equipment available on each unit for them were compared with the resource requirements stated in the recommendations. The seven units without any recognised intensive care cots were assumed to have to be able to equip one cot to intensive care level 1 in the short term to allow adequate support for infants before transfer to another centre. Any shortfalls to these requirements were noted and the cost (including value added tax) of purchasing that equipment calculated. In addition, the cost of replacing items over 5 years old was calculated. The prices used were quoted at the time of the study. For the analysis the neonatal units in the region were divided into groups. Group I included those carrying out more than 500 days of level 1 intensive care per year (five units with 35 recognised cots) and two groups of those doing less (12 units with 10 recognised cots): those units with recognised
Child Health, Leicester

Royal Infirmary, PO Box 65

BrMed f 1990;301:201-3 


\begin{tabular}{|c|c|c|c|c|c|c|c|c|c|c|c|c|}
\hline & \multicolumn{4}{|c|}{ Group I (35 cots) } & \multicolumn{4}{|c|}{ Group II (10 cots) } & \multicolumn{4}{|c|}{ Group III ( 7 cots) } \\
\hline & \multicolumn{2}{|c|}{$\begin{array}{l}\text { Additional } \\
\text { equipment }\end{array}$} & \multicolumn{2}{|c|}{$\begin{array}{c}\text { Equipment } \\
>5 \text { years old } \\
\text { (replacement) }\end{array}$} & \multicolumn{2}{|c|}{$\begin{array}{l}\text { Additional } \\
\text { equipment }\end{array}$} & \multicolumn{2}{|c|}{$\begin{array}{c}\text { Equipment } \\
>5 \text { years old } \\
\text { (replacement) }\end{array}$} & \multicolumn{2}{|c|}{$\begin{array}{l}\text { Additional } \\
\text { equipment }\end{array}$} & \multicolumn{2}{|c|}{$\begin{array}{c}\text { Equipment } \\
>5 \text { years old } \\
\text { (replacement) }\end{array}$} \\
\hline & No & Cost & No & Cost & No & Cost & No & Cost & No & Cost & No & Cost \\
\hline Incubators & & & 17 & 117000 & & & 1 & 6900 & & & 2 & 13800 \\
\hline Cardioraters & & & 6 & 8300 & 1 & 1400 & & & 1 & 1400 & & \\
\hline Apnoea monitors & 4 & 1900 & 14 & 6400 & 1 & 500 & & & & & & \\
\hline Blood pressure monitors & 22 & 45500 & 4 & 8300 & 4 & 8300 & 7 & 14500 & 1 & 2100 & & \\
\hline Transcutaneous $\mathrm{PO}_{2}$ monitors & 3 & 7900 & 11 & 29100 & & & 5 & 13200 & 1 & 2700 & & \\
\hline Infusion pumps & 2 & 2800 & 29 & 40000 & 1 & 1400 & 16 & 22100 & 6 & 8300 & 4 & 5500 \\
\hline Syringe pumps & 11 & 8200 & 24 & 16000 & 3 & 2200 & 10 & 7500 & 1 & 800 & 3 & 2200 \\
\hline Phototherapy units & & & 25 & 34500 & 1 & 1400 & 7 & 9700 & & & 2 & 2800 \\
\hline Ventilators & & & 16 & 110400 & & & 4 & 27600 & 1 & 6900 & 1 & 6900 \\
\hline
\end{tabular}

intensive care cots (group II; five units) and those without (group III; seven units).

\section{Results}

There was a great deal of variation in the units both in the amount of equipment available and the items over 5 years old. Table I lists the total number of items required (new equipment and replacements for those items over 5 years old) and their cost in each of the groups, and on first inspection it would seem that units in group I require more equipment (both additional and replacement) than those in groups II and III. Across the region as a whole, however, the average cost per cot to bring recognised cots up to the recommended equipment levels and to replace equipment over 5 years old was similar in groups I and II (table II). Though comparatively less would have to be spent to replace equipment over 5 years old in the units in group III, comparatively more seems to be required for providing additional equipment to achieve recommended levels. The total cost (including value added tax) would be just over $£ 600000$.

TABLE II -Cost (£; including VAT) of providing equipment deficit and replacing items more than 5 years old to equip all cots (whether recognised or not) to intensive care level 1 standard

\begin{tabular}{lcrrr}
\hline & $\begin{array}{c}\text { Additional } \\
\text { equipment } \\
\text { (average per cot) }\end{array}$ & $\begin{array}{r}\text { Replacement } \\
\text { equipment } \\
\text { (average per cot) }\end{array}$ & \multicolumn{1}{c}{ Total } \\
\hline Group I (35 cots) & $66300(1900)$ & $370900(10600)$ & 437200 \\
Group II (10 cots) & $15100(1500)$ & $101400(10100)$ & 116500 \\
Group III (7 cots) & $22000(3100)$ & $31200(4500)$ & 53200 \\
\hline Total & & & 606900 \\
\hline
\end{tabular}

Obviously not all cots will be used for level 1 intensive care continuously, and equipping cots to perform intensive care level 2 would be cheaper. There are no national guidelines for level 2 equipment, so we used the British Paediatric Association and British Association of Perinatal Paediatrics definitions of infants requiring this level of care to establish an equipment requirement. This was similar to the level 1 requirement but omitted a ventilator and had only half

TABLE III-Cost (£; including VAT) of providing equipment deficit and replacing items more than 5 years old to equip all recognised intensive care cots to intensive care levels 1 and 2 in a ratio of $1: 1 \cdot 37$. Units with only one intensive care cot (whether recognised or not) were assumed to equip to level 1 care

\begin{tabular}{lcrr}
\hline & $\begin{array}{c}\text { Additional } \\
\text { equipment } \\
\text { (average per cot) }\end{array}$ & $\begin{array}{c}\text { Replacement } \\
\text { equipment } \\
>5 \text { years old } \\
\text { (average per cot) }\end{array}$ & Total \\
\hline Group I (35 cots) & $55900(1600)$ & $253800(7300)$ & 309700 \\
Group II (10 cots) & $13000(1300)$ & $81600(8200)$ & 94600 \\
Group III (7 cots) & $22000(3100)$ & $31200(4500)$ & 53200 \\
\hline Total $^{\cdot}$ & & & 457500 \\
\hline
\end{tabular}

the number of intravenous infusion devices. It has recently been shown that the ratio of level 1 to level 2 intensive care is approximately $1: 1 \cdot 37 .{ }^{4}$ We therefore performed a cost analysis dividing the number of available cots in this ratio. Units with only one cot (whether recognised or not) were again assumed to need equipping to level 1 standard. The results (table III) show that the average cost per cot in groups I and II is similar for both additional and replacement equipment. With this analysis the total cost is reduced by about $25 \%$ to just over $£ 450000$.

\section{Discussion}

Some care has to be taken in interpreting these data. Opinions may differ on what items of equipment are necessary to provide adequate level 1 intensive care, and clearly an individual unit's preferences for monitors with single or combined functions, for example, will affect cost. Additionally, items such as incubators (which contribute $23 \%$ of the total cost) will have a longer useful life than five years. Against this must be weighed the fact that we have not made any allowance for infants requiring special care, who constitute three quarters of all admissions within the Trent neonatal service. ${ }^{4}$ These infants are a heterogeneous group, but a large proportion will require basic equipment such as incubators, cardioraters, and infusion pumps at some stage while in the unit. Clearly, the demands of these infants will add considerably to equipment costs. The purchase and upkeep of major items such as blood gas analysers and ultrasound scanners will also have a great effect on the equipment costs of units doing much intensive care as these units require such items to be on site rather than simply available in other hospital departments, which would suffice in less busy units.

In general terms, the average extra funding required for additional equipment for those units without recognised cots seemed higher than for those with funded cots. This may have been due to the fact that the additional equipment requirement for one of these units accounted for over half of the total in that group, but again this probably reflects the generally poor level of equipment provision in this type of unit.

Comparing the costs in tables II and III shows that equipping recognised cots for intensive care levels 1 and 2 in the expected proportion of these levels of care reduces total costs by about $25 \%$. However, the recognised cots will be used for periods with a greater proportion of level 1 care, and providing equipment to these expected levels will clearly impair a unit's ability to provide its full potential of level 1 care.

Before any reforms regarding funding of health services are implemented important decisions must be made both by clinicians and by government. Clinicians need to revise the existing recommendations for essential equipment and to establish with manufacturers the useful life span of individual items before 
negotiating their budgets. The recommendations will have to include adequate provision for equipment costs, unlike the current situation where, owing to financial constraints, no replacement policy exists and a great deal of equipment is provided from charitable donations. We have estimated the equipment shortfall within only the neonatal service, but it is likely that a similar situation exists in other specialties. Although not all of these disciplines depend as heavily on equipment for their day to day work as does the neonatal service, such shortfalls inevitably detract from optimal clinical care.

As far as government is concerned, the setting up of budget holding units should parallel industrial privatisation, with current shortfalls in provision of equipment being likened to outstanding debts. Writing off these debts using government funds would prevent budget holders having to cope with an inherited chronic shortfall in the provision of appropriate equipment, which would adversely affect their operating costs. The government clearly thought that such a move was vital before it sold off Rover. To correct all such deficiencies before introducing new contracts would require a large injection of capital, but this measure might mean the difference between success and failure for a marketplace economy for health services

We thank all 17 perinatal units in the Trent region who cooperated with this study. Funding was provided by the regional health authority. ACF is supported by the Spastics Society.

\section{Appendix}

The following equipment (No of items) is recommended by the British Paediatrics Association and British Association of Perinatal Paediatrics to be available for each baby receiving intensive care:

Intensive care incubator or unit with overhead heating (1) Respiratory or apnoea monitor (1)

Intravascular blood pressure transducer or surface blood pressure recorder $(1)$

Transcutaneous $\mathrm{Po}_{2}$ monitor or intravascular oxygen transducer (1)

Transcutaneous $\mathrm{PCO}_{2}$ monitor (1)

Syringe pumps (2)

Infusion pumps (2)

Ventilator (1)

Continuous temperature monitor $(1)$

Phototherapy unit (1)

Ambient oxygen monitor (1)

Facilities for frequent blood gas analysis using micromethods

Facilities for frequent biochemical analysis including glucose, bilirubin, and electrolytes by micromethods

Access to ultrasound equipment for visualisation of organs such as the brain

Access to equipment for radiological examination

1 Ryan S, Sics A, Congdon P. Cost of neonatal care. Arch Dis Child 1988;63 303-6.

Royal College of Physicians of London. Medical care of the newborn in England and Wales. London: Royal College of Physicians, 1988.

British Paediatric Association, British Association of Perinatal Paediatrics. Categories of babies requiring neonatal care. London: British Paediatric Categones of babies requiring neonatal care. London: British
Association/British Association of Perinatal Paediatrics, 1984.

4 Field DJ, Hodges S, Mason E, Burton P, Yates J, Wale S. The demand for neonatal intensive care. Br Med f 1989;299:1305-8.

(Accepted 15 May 1990)
Physical Education

Association Research

Centre and Schools of Education and

Postgraduate Medicine, University of Exeter, Exeter EX1 2LU

Neil Armstrong, PHD, senior lecturer

John Balding, MMEDSCI, senior lecturer

Peter Gentle, FFCM, honorary

senior lecturer

Brian Kirby, FRCP, senior lecturer

Correspondence to: Dr Neil Armstrong, Physical Education Association Research Centre, School of Education, University of Exeter, Excter EX1 2LU.

BrMed f 1990;301:203-5

\title{
Patterns of physical activity among 11 to 16 year old British children
}

\author{
Neil Armstrong, John Balding, Peter Gentle, Brian Kirby
}

\begin{abstract}
Objective-To examine the patterns of physical activity among British schoolchildren aged 11 to 16 and to assess whether the children experience the intensity and duration of physical activity that are believed to stress the cardiopulmonary system appropriately.
\end{abstract}

Design-Cross sectional study of a sample of children drawn from a larger survey of coronary risk factors in children. Continuous monitoring of heart rate for 12 hour periods on three school days and one Saturday.

Setting - Two communities in Devon.

Subjects - 266 Children (163 girls, 103 boys) aged 11 to 16 randomly selected from a sample of 707 children.

Main outcome measures-Percentage of time and number of sustained periods in which heart rate was $>139$ beats $/ \mathrm{min}$. Anthropometric measures and external assessment of sexual maturity with Tanner's indices.

Results - The boys had heart rates $>139$ beats/ min for a significantly higher percentage of time than the girls $(p<0.01)$ during the weekday $(6.2 \% v 4.3 \%)$ and the Saturday $(5.6 \% v 2.6 \%)$. The boys had significantly more five and $\mathbf{1 0}$ minute periods with heart rates $>139$ beats/min than the girls during the Saturday and weekdays and more 20 minute periods during the weekdays. 84 Girls and 37 boys had no 10 minute period with a heart rate $>139$ beats/min during the three weekdays and 112 girls and 65 boys had no such 10 minute period during the Saturday. No significant relation was detected in either sex between the amount or habitual physical activity (heart rate) and skinfold thickness or maturity group.

Conclusions-British children have surprisingly low levels of habitual physical activity, and many children seldom undertake the volume of physical activity believed to benefit the cardiopulmonary system. Boys are more active than girls. The pubertal stage of development or body fatness, or both, do not seem to be sensitive indicators of physical activity in either girls or boys.

\section{Introduction}

Simons-Morton et al recently reviewed published recommendations for physical activity for children and concluded that appropriate physical activity entailed dynamic movement of large muscle groups for 20 minutes or longer, three or more times a week, at an intensity eliciting heart rates $\geqslant 140$ beats/min (roughly $70 \%$ of the maximal heart rate). ${ }^{1}$ Whether British children regularly undertake this degree of physical activity was unknown. We therefore examined the patterns of physical activity among British schoolchildren aged 11 to 16 and assessed the amount of appropriate physical activity.

\section{Subjects and methods}

We invited all children in state school years seven to 10 in two well defined communities in Devon to participate in a research project on the prevalence of coronary risk factors in children. The two localities surveyed were broadly comparable with much of 